\title{
Successful Use of Extracorporeal Membrane Oxygenation in a Hematopoietic Stem Cell Transplant Patient With Idiopathic Pneumonia Syndrome
}

\author{
Wen-I Liao MD, Shih-Hung Tsai MD, and Sheng-Kang Chiu MD
}

\begin{abstract}
We report the case of an adult patient with idiopathic pneumonia syndrome following allogeneic hematopoietic stem cell transplantation, which was successfully managed with venovenous extracorporeal membrane oxygenation (ECMO) and immunosuppressive therapy. A 30-year-old man with precursor B cell acute lymphocytic leukemia had received chemotherapy 10 years previously, with complete remission. He underwent allogeneic hematopoietic stem cell transplantation 4 months prior to enrollment, owing to leukemia relapse. One hundred thirty days post-transplant the patient developed shortness of breath, nonproductive cough, and low-grade fever for 1 week. He subsequently developed acute hypercapnic and hypoxic respiratory failure that was unresponsive to conventional medical therapy. He was successfully managed with venovenous ECMO for 19 days, with complete resolution of his respiratory symptoms. Thus, judicious use of ECMO as a bridge before steroid and other conventional therapy take effect in patients with isolated respiratory failure appears justified. Key words: idiopathic pneumonia syndrome; extracorporeal membrane oxygenation; hematopoietic stem cell transplantation; respiratory failure; adult; acute lymphocytic leukemia. [Respir Care 2013;58(2):e6-e10. (C) 2013 Daedalus Enterprises]
\end{abstract}

\section{Introduction}

Allogeneic hematopoietic stem cell transplantation (HSCT) is a curative treatment option for a variety of hematological disorders. Pulmonary complications develop in $25-60 \%$ of HSCT recipients and account for approximately $50 \%$ of transplant-related deaths. ${ }^{1-3}$ Pulmonary complications after HSCT include infectious or noninfectious causes, defined as early or late, according to the time of onset after transplant. Idiopathic pneumonia syndrome describes a clinical entity of diffuse lung injury that

Drs Liao and Tsai are affiliated with the Department of Emergency Medicine; and Dr Chiu is affiliated with the Division of Infectious Diseases and Tropical Medicine, Department of Internal Medicine, TriService General Hospital, National Defense Medical Center, Taipei, Taiwan.

The authors have disclosed no conflicts of interest.

Correspondence: Sheng-Kang Chiu MD, Division of Infectious Diseases and Tropical Medicine, Department of Internal Medicine, TriService General Hospital, 325 Chenggong Road, Section 2, Neihu District, Taipei City 11490 Taiwan, Republic of China. E-mail: skchiu@ndmctsgh.edu.tw.

DOI: $10.4187 /$ respcare. 01716 occurs around 90 days post-transplant and for which no infectious cause can be identified. ${ }^{4}$

Venovenous extracorporeal membrane oxygenation (VV ECMO) can provide temporary lung function in patients with potentially reversible respiratory failure, while waiting for a response to conventional therapy. ECMO may be used as salvage therapy in critical patients with refractory gas-exchange failure. A multicenter trial study has demonstrated that ECMO can improve survival in adult patients with severe respiratory failure, whose Murray scores exceed 3.0 or who have a $\mathrm{pH}$ of $<7.2 .{ }^{5}$ Adult patients with malignancy and who develop respiratory or cardiac failure can be offered ECMO with a small but realistic expectation of survival. ${ }^{6}$

We describe the successful use of VV ECMO in an adult patient who developed idiopathic pneumonia syndrome with intractable respiratory failure after undergoing HSCT. To our knowledge, this is the first case in which VV ECMO was successfully used to remedy post-HSCT idiopathic pneumonia syndrome in an adult patient.

\section{Case Report}

A 30-year-old man with precursor B cell acute lymphocytic leukemia received chemotherapy 10 years ago, re- 
sulting in complete remission. He had undergone allogeneic HSCT 4 months previously, following leukemia relapse. The immunosuppressant agent cyclosporine was administered post-transplant, and the dose was gradually tapered over 4 months, from $800 \mathrm{mg} / \mathrm{d}$ to $200 \mathrm{mg} / \mathrm{d}$.

One hundred thirty days post-transplant the patient developed a 1-week-long progressive shortness of breath, nonproductive cough, and low-grade fever. On arrival his blood pressure was $98 / 43 \mathrm{~mm} \mathrm{Hg}$, pulse rate 122 beats/ min, breathing frequency 32 breaths/min, and body temperature $38.2^{\circ} \mathrm{C}$. A physical examination disclosed bilateral crackle breathing sounds, labored breathing, and intercostal retractions. There was no maculopapular rash on the skin. The chest radiograph revealed bilateral groundglass opacity and patchy infiltrates. The electrocardiogram showed sinus tachycardia. Echocardiography showed good biventricular function. The laboratory tests revealed mild respiratory acidosis $\left(\mathrm{pH} 7.345, \mathrm{P}_{\mathrm{aCO}_{2}} 42.4 \mathrm{~mm} \mathrm{Hg}, \mathrm{HCO}_{3}{ }^{-}\right.$ $22.9 \mathrm{mmol} / \mathrm{L}$, and $\mathrm{P}_{\mathrm{aO}_{2}} 94 \mathrm{~mm} \mathrm{Hg}$ under non-rebreathing mask at $15 \mathrm{~L} / \mathrm{min})$. The white-blood-cell count was $11.9 \times 10^{3}$ cells $/ \mu \mathrm{L}$, with $65 \%$ neutrophils, the platelet count was $173 \times 10^{3}$ cells $/ \mu \mathrm{L}$, and the hemoglobin level was $11.9 \mathrm{~g} / \mathrm{dL}$.

Endotracheal intubation was performed, following progressive respiratory distress in the emergency department, and the patient was admitted to our ICU, where he was treated with a broad-spectrum antibacterial agent and ventilator support. On ICU day 7, ganciclovir was administered for the possibility of cytomegalovirus infection. However, the bilateral ground-glass opacity of chest radiography persisted and all cultures of urine, blood, and sputum were negative. The $\mathrm{P}_{\mathrm{aO}} / \mathrm{F}_{\mathrm{IO}_{2}}$ was $209 \mathrm{~mm} \mathrm{Hg}$ and the Murray score was 1.5 on ICU day 10. On ICU day 18, despite an increase in peak inspiratory pressure (PIP) up to $26 \mathrm{~cm} \mathrm{H}_{2} \mathrm{O}$, the worsening hypercapnia was persistent $\left(\mathrm{pH} 7.233, \mathrm{P}_{\mathrm{aCO}_{2}}\right.$ $71.5 \mathrm{~mm} \mathrm{Hg}, \mathrm{HCO}_{3}{ }^{-} 29.5 \mathrm{mmol} / \mathrm{L}, \mathrm{P}_{\mathrm{aO}_{2}} / \mathrm{F}_{\mathrm{IO}_{2}} 131 \mathrm{~mm} \mathrm{Hg}$ ), with a Murray score of 3 . The ventilator mode was pressure regulated volume control, tidal volume was $6.2 \mathrm{~mL} /$ $\mathrm{kg}$, PEEP was $14 \mathrm{~cm} \mathrm{H} \mathrm{H}_{2} \mathrm{O}$, and $\mathrm{F}_{\mathrm{IO}_{2}}$ was 0.8. A highresolution computed tomography scan showed bilateral ground-glass opacities and cylindrical bronchiectasis associated with lower lobe volume loss (Fig. 1A).

A neuromuscular blocking agent, cisatracurium, was initiated at a dose of $0.2 \mathrm{mg} / \mathrm{kg}$ on ICU day 18 , and the ventilation improved transiently. A tracheostomy was performed on ICU day 20. On ICU day 25 the patient's condition was relatively stable, with a $\mathrm{P}_{\mathrm{aO}_{2}} / \mathrm{F}_{\mathrm{IO}_{2}}$ of $196 \mathrm{~mm} \mathrm{Hg}$, a Murray score 2.6, and a PIP $30 \mathrm{~cm} \mathrm{H}_{2} \mathrm{O}$.

The patient's family approved an open minimal thoracotomy with lung biopsy. The pathological report revealed variable thickness of the alveolar wall, intraluminal fibroblastic tissue, diffuse uniform inflammatory infiltrates of lymphocytes, and plasma cells in the interstitial fluid. The
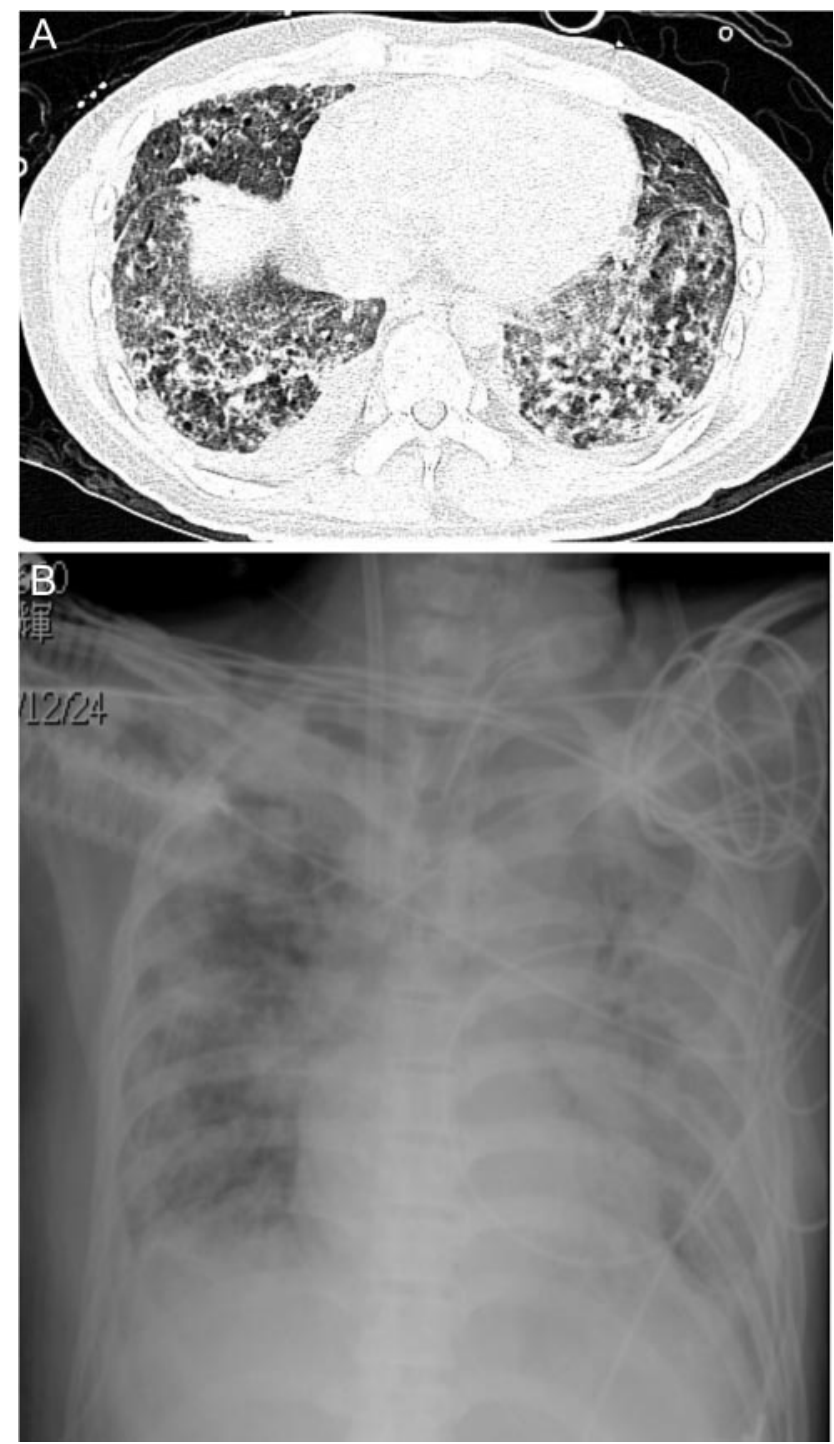

Fig. 1. A: High-resolution computed tomography scan shows bilateral ground-glass opacities and cylindrical bronchiectasis associated with lower lobe volume loss. B: Chest radiograph immediately after cannulation for venovenous extracorporeal membrane oxygenation on ICU day 28 reveals sharply deteriorated bilateral ground-glass opacities and patchy consolidations.

pathological report was consistent with non-specific interstitial pneumonia. No evidence of malignancy or leukemia relapse was noted by microscopy. In addition, no bacterial, fungal, or viral infection was found on specimen examination, culture, or by polymerase chain reaction. On ICU day 26, steroid therapies, consisting of intravenous methylprednisolone $(1,000 \mathrm{mg} / \mathrm{d})$, were administered for 3 consecutive days and followed with $2 \mathrm{mg} / \mathrm{kg} /$ dose every 12 hours. However, the refractory hypercapnic and hypoxemic respiratory failure further worsened on ICU day 27 $\left(\mathrm{P}_{\mathrm{aCO}}\right.$ reaching $125 \mathrm{~mm} \mathrm{Hg}$ and $\mathrm{P}_{\mathrm{aO}_{2}} / \mathrm{F}_{\mathrm{IO}_{2}} 89 \mathrm{~mm} \mathrm{Hg}$, Murray score 3.75, lung compliance $8 \mathrm{~mL} / \mathrm{cm} \mathrm{H}_{2} \mathrm{O}$ ) under 

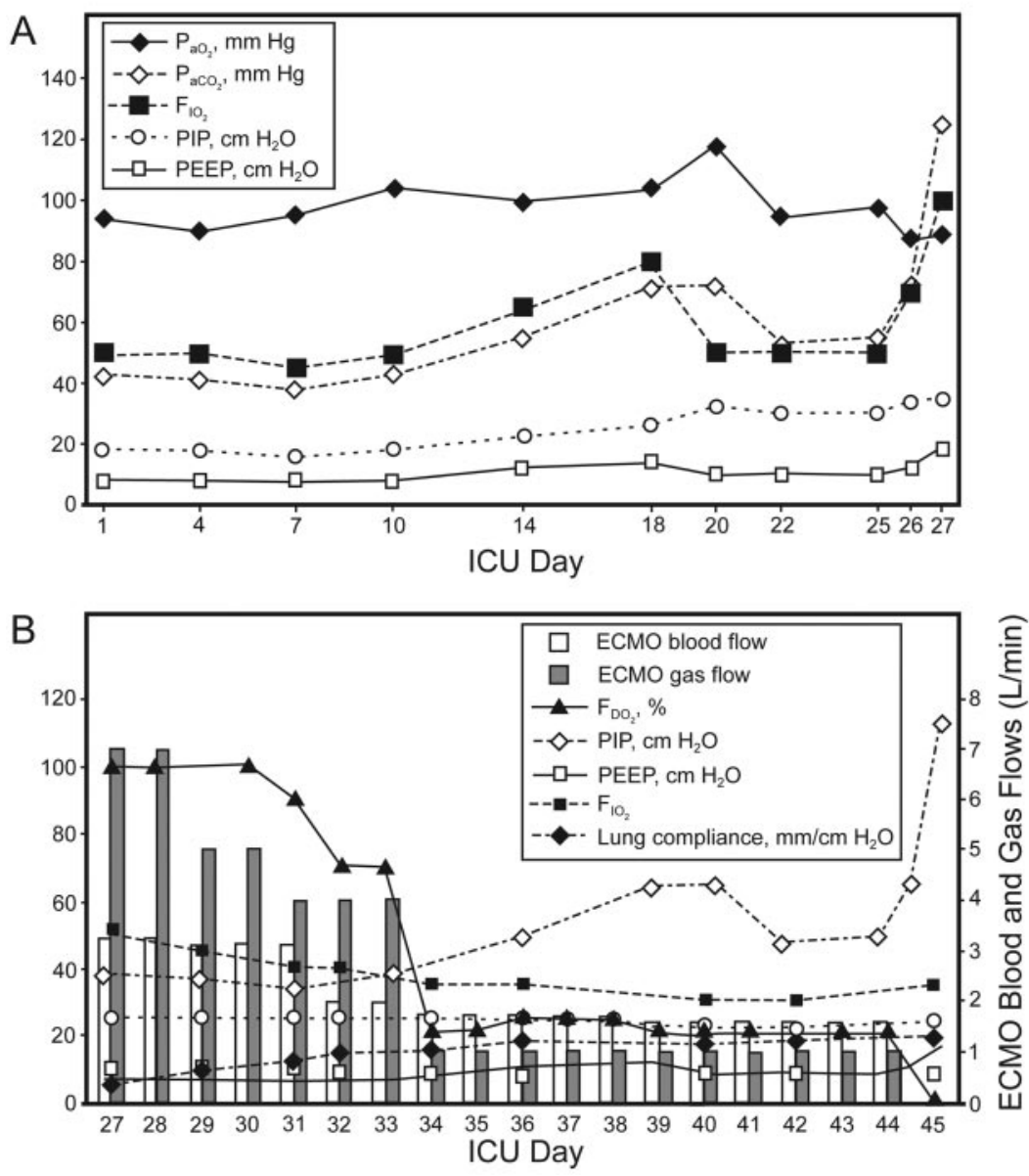

Fig. 2. Schematic representations of the clinical course and ventilator settings in the ICU. A: Ventilator settings and blood gas values from ICU days 1 through 27. B: Ventilator and extracorporeal membrane oxygenation (ECMO) settings from ICU days 27 through 45 . PIP $=$ peak inspiratory pressure. $\mathrm{F}_{\mathrm{DO}_{2}}$ = fraction of delivered oxygen to the oxygenator.

the ventilator settings PIP $35 \mathrm{~cm} \mathrm{H}_{2} \mathrm{O}$, breathing frequency 35 breaths/min, PEEP $18 \mathrm{~cm} \mathrm{H} \mathrm{O}_{2}$, and $\mathrm{F}_{\mathrm{IO}_{2}} 1.0$.

We decided to add VV ECMO support for lung rest while waiting for the patient's response to steroid therapy. In the ICU, the right femoral vein was cannulated with a 23 French cannula for venous drainage, and a 21 French cannula inserted into the right internal jugular vein, for return of oxygenated blood. The circuit consisted of a centrifugal pump (Biomedicus 560, Medtronic, Minneapolis, Minnesota) and an oxygenator (Affinity NT, Medtronic, Minneapolis, Minnesota). The patient was anticoagulated with heparin to maintain an activated clotting time of 160-180 s. The patient received low-dose dopamine and a 4 unit packed red blood products transfusion for the transient hypotension $(50 / 30 \mathrm{~mm} \mathrm{Hg})$ while the ECMO was starting. Dormicum and cisatracurium were used for sedation during cannulation. The chest radiograph taken immediately after cannulation for VV ECMO revealed sharply deteriorated bilateral ground-glass opacities and patchy consolidations (see Fig. 1B). ECMO was started with a median extracorporeal blood flow of $3.34 \mathrm{~L} / \mathrm{min}$ and a gas flow of $7 \mathrm{~L} / \mathrm{min}$ of $100 \%$ oxygen. The patient's initial "resting" ventilator setting was tidal volume $4 \mathrm{~mL} / \mathrm{kg}, \mathrm{F}_{\mathrm{IO}_{2}} 0.50$, PIP $25 \mathrm{~cm} \mathrm{H} \mathrm{H}_{2} \mathrm{O}$, PEEP $10 \mathrm{~cm} \mathrm{H}_{2} \mathrm{O}$, breathing frequency 10 breaths/min, and pressure-control mode.

On ICU day 32 we were able to progressively reduce the extracorporeal blood flow to $1.98 \mathrm{~L} / \mathrm{min}$, the gas flow to $4 \mathrm{~L} / \mathrm{min}$ of $70 \%$ oxygen, and the ventilator settings to $\mathrm{F}_{\mathrm{IO}_{2}} 0.4$, PIP $20 \mathrm{~cm} \mathrm{H}_{2} \mathrm{O}$, PEEP $8 \mathrm{~cm} \mathrm{H}_{2} \mathrm{O}$, and pressuresupport mode. The lung compliance increased to $14 \mathrm{~mL} /$ $\mathrm{cm}_{2} \mathrm{O}$. On ICU day 36, further reduction of ECMO settings occurred, to extracorporeal blood flow of $1.7 \mathrm{~L} /$ min and gas flow of $1 \mathrm{~L} / \mathrm{min}$ of $35 \%$ oxygen, with the lung compliance at $18 \mathrm{~mL} / \mathrm{cm} \mathrm{H}_{2} \mathrm{O}$. Methylprednisolone weaning involved a slow taper to a dose of $1 \mathrm{mg} / \mathrm{kg} / \mathrm{d}$ at the time of ICU discharge.

On ICU day 43 the follow-up chest radiograph revealed resolution of bilateral ground glass under steroid therapy. No obvious changes of the ventilator settings occurred 


\section{ECMO in Hematopoietic Stem Cell Transplant Patient}

over the next few days. On ICU day 40, breathing trials were attempted without ECMO support. On ICU day 45 the $\mathrm{P}_{\mathrm{aO}_{2}} / \mathrm{F}_{\mathrm{IO}_{2}}$ could be maintained at $200 \mathrm{~mm} \mathrm{Hg}$ under PIP of $24 \mathrm{~cm} \mathrm{H} \mathrm{H}_{2} \mathrm{O}$, PEEP of $8 \mathrm{~cm} \mathrm{H} \mathrm{H}_{2} \mathrm{O}, \mathrm{F}_{\mathrm{IO}_{2}} 0.35$, and breathing frequency of 12 breaths/min, with pressure-support mode, without ECMO support. We successfully discontinued ECMO and sedation, without ECMO-related complications, and placed the patient back on conventional ventilation with an $\mathrm{F}_{\mathrm{IO}_{2}}$ of 0.4 . The steroid therapy shifted to oral prednisolone $(0.8 \mathrm{mg} / \mathrm{kg} / \mathrm{d})$ for 2 months. The patient was weaned to a ventilator and discharged from the ICU with a good clinical recovery on ICU day 52. Figure 2 illustrates a schematic representation of the clinical course and ventilator settings in the ICU. Six months later the patient was still alive and in good condition.

\section{Discussion}

The outcome of infectious pulmonary complications after HSCT has recently improved, resulting from advances in antimicrobial therapy, including those against invasive fungal infection. ${ }^{7}$ However, late-onset noninfectious pulmonary complications after HSCT still remain potentially life threatening for HSCT recipients. ${ }^{8}$ In this case, ECMO support with immunosuppressive therapy was used to rescue idiopathic pneumonia syndrome post-HSCT with intractable hypercapnic and hypoxemic respiratory failure. ECMO provided a period of lung rest while waiting for the patient's response to immunosuppressive therapy.

Late-onset noninfectious pulmonary complications generally describe various pathologies that start to appear around 90 days after transplant, and include bronchiolitis obliterans, bronchiolitis obliterans with organizing pneumonia, and idiopathic pneumonia syndrome. ${ }^{9}$ Breathlessness, a nonproductive cough, hypoxemia, and non-lobar radiographic infiltrates are classic presentations of idiopathic pneumonia syndrome. ${ }^{10}$ Fever is present in a minority of patients. ${ }^{10}$ The appearances of idiopathic pneumonia syndrome on high-resolution computed tomography are bilateral, symmetric, lower lobe peripherally predominant ground-glass opacity with traction bronchiectasis, and lower lobe volume loss. ${ }^{10}$ The key histopathologic features of idiopathic pneumonia syndrome are the uniformity of the interstitial inflammation, which consists mainly of lymphocytes and some plasma cells. The alveolar wall has varying degrees of fibrosis but no honeycombing, as seen in the usual interstitial pneumonia. ${ }^{10}$ Possible causes of idiopathic pneumonia syndrome include chemoradiation damage, unrecognized infection, and immunologically mediated injury related to graft versus host disease. ${ }^{11}$

The overall survival rate of HSCT recipients with late-onset noninfectious pulmonary complications is significantly worse than HSCT recipients without late-onset noninfectious pulmonary complications. ${ }^{12}$ The treatment response rate is quite low in patients with idiopathic pneumonia syndrome. ${ }^{13}$ Once patients have developed lateonset noninfectious pulmonary complications, early steroid administration is significantly associated with a better final outcome. The recommended dosage of corticosteroid is $0.5-1.0 \mathrm{mg} / \mathrm{kg}$, as soon as possible after an infectious etiology has been excluded. ${ }^{12}$ However, the time period of reversibility of pulmonary damage after administering steroid therapy is difficult to predict. In our patient, steroid therapy was not administered early in the course of the disease because of the patient's persistent low-grade fever, patchy infiltrate on chest radiography, and the immunocompromised status. Atypical pathogenic, fungal, and viral infections were still considered, and immunosuppressive therapy was delayed until complete lung specimen examination was performed. Although steroid therapy was started immediately after diagnosis of idiopathic pneumonia syndrome in our patient, it was too late to take effect in this critical situation. In order to save the patient, who had isolated respiratory failure, VV ECMO was used and served as a stopgap measure until conventional treatment could take effect.

A variety of therapies have been attempted to improve adult respiratory failure outcomes, including lower tidal volumes, recruitment maneuvers, high frequency oscillation, corticosteroids, inhaled nitric oxide, prone position, and aerosolized surfactant. ${ }^{14,15}$ In patients failing all conventional and alternative methods of treatment, ECMO has been proposed. ${ }^{6} \mathrm{VV}$ ECMO can supply oxygenation and ventilation, and thus it lowers the ventilator settings and can prevent oxygen toxicity and high airway pressure-related lung damage. The use of VV ECMO is a rescue therapy in patients with acute, reversible, and lifethreatening respiratory failure who have been unsuccessful with all advanced modes of mechanical ventilation.

As determined by the Extracorporeal Life Support Organization, adults with malignancy and respiratory or cardiac failure can be offered ECMO with a small but real expectation for survival. ${ }^{6}$ A series of 72 adults with a diagnosis of malignancy, who developed cardiac or pulmonary failure requiring ECMO, were studied. Of these, 44 patients $(61 \%)$ died while on their ECMO treatments, $23(32 \%)$ survived to hospital discharge, and $5(7 \%)$ survived ECMO but died before discharge. Among the 72 patients, 4 patients had undergone HSCT. Two of the 4 patients survived to discharge. The survival to discharge appears greater than the previously perceived outcomes in cancer patients with cardiopulmonary failure, which has been associated with a historically high risk of mortality. ${ }^{6}$ More recent case reports have demonstrated that ECMO is life-saving in post-HSCT pediatric patients with diffuse alveolar hemorrhage, bronchiolitis obliterans, and severe bronchiolitis. ${ }^{16-18}$ Reports of ECMO implantations in postHSCT adult patients have been somewhat limited. How- 


\section{ECMO in Hematopoietic Stem Cell Transplant Patient}

ever, when clinicians are considering ECMO, placing them earlier may be helpful in reducing lung injury. The ideal "resting" ventilator setting and weaning strategy for patients with severe respiratory failure, who are receiving ECMO, are still unknown. However, $\mathrm{PIP}$ of $20-25 \mathrm{~cm} \mathrm{H}_{2} \mathrm{O}$, breathing frequency of 10 breaths/min, and adequate PEEP of $8-15 \mathrm{~cm} \mathrm{H}_{2} \mathrm{O}$ have been suggested by experts. ${ }^{5,19,20}$ Offering ECMO in post-HSCT patients with respiratory failure poses ethical dilemmas to clinicians and families. Clinicians need to have detailed discussions with families, presenting them with the current research on ECMO before proceeding. Judicious use of this technology in patients with isolated respiratory failure in a center with established expertise in ECMO appears justified.

We report an adult post-HSCT patient with idiopathic pneumonia syndrome, who was successfully managed with ECMO and immunosuppressive therapy. Judicious use of ECMO in patients with isolated respiratory failure may serve as a bridge before steroid and other conventional therapies take effect. Our experience has the potential to improve the care of respiratory failure in HSCT recipients.

\section{REFERENCES}

1. Wang JY, Chang YL, Lee LN, Chen JH, Tang JL, Yang PC, et al. Diffuse pulmonary infiltrates after bone marrow transplantation: the role of open lung biopsy. Ann Thorac Surg 2004;78(1):267-272.

2. Yen KT, Lee AS, Krowka MJ, Burger CD. Pulmonary complications in bone marrow transplantation: a practical approach to diagnosis and treatment. Clin Chest Med 2004;25(1):189-201.

3. Griese M, Rampf U, Hofmann D, Fuhrer M, Reinhardt D, BenderGotze C. Pulmonary complications after bone marrow transplantation in children: twenty-four years of experience in a single pediatric center. Pediatr Pulmonol 2000;30(5):393-401.

4. Clark JG, Hansen JA, Hertz MI, Parkman R, Jensen L, Peavy HH. NHLBI workshop summary. Idiopathic pneumonia syndrome after bone marrow transplantation. Am Rev Respir Dis 1993;147(6 Pt 1): 1601-1606.

5. Peek GJ, Mugford M, Tiruvoipati R, Wilson A, Allen E, Thalanany $\mathrm{MM}$, et al. Efficacy and economic assessment of conventional ventilatory support versus extracorporeal membrane oxygenation for severe adult respiratory failure (CESAR): a multicentre randomised controlled trial. Lancet 2009;374(9698):1351-1363.

6. Gow KW, Lao OB, Leong T, Fortenberry JD. Extracorporeal life support for adults with malignancy and respiratory or cardiac failure: the Extracorporeal Life Support experience. Am J Surg 2010;199(5): 669-675.

7. Upton A, Kirby KA, Carpenter P, Boeckh M, Marr KA. Invasive aspergillosis following hematopoietic cell transplantation: outcomes and prognostic factors associated with mortality. Clin Infect Dis 2007;44(4):531-540.

8. Sakaida E, Nakaseko C, Harima A, Yokota A, Cho R, Saito Y, et al. Late-onset noninfectious pulmonary complications after allogeneic stem cell transplantation are significantly associated with chronic graft-versus-host disease and with the graft-versus-leukemia effect. Blood 2003;102(12):4236-4242.

9. Afessa B, Litzow MR, Tefferi A. Bronchiolitis obliterans and other late onset non-infectious pulmonary complications in hematopoietic stem cell transplantation. Bone Marrow Transplant 2001; 28(5):425-434.

10. Travis WD, Hunninghake G, King TE Jr, Lynch DA, Colby TV, Galvin JR, et al. Idiopathic nonspecific interstitial pneumonia: report of an American Thoracic Society project. Am J Respir Crit Care Med 2008;177(12):1338-1347.

11. Clark JG, Madtes DK, Martin TR, Hackman RC, Farrand AL, Crawford SW. Idiopathic pneumonia after bone marrow transplantation: cytokine activation and lipopolysaccharide amplification in the bronchoalveolar compartment. Crit Care Med 1999;27(9):1800-1806.

12. Ueda K, Watadani T, Maeda E, Ota S, Kataoka K, Seo S, et al. Outcome and treatment of late-onset noninfectious pulmonary complications after allogeneic haematopoietic SCT. Bone Marrow Transplant 2010;45(12):1719-1727.

13. Nishio N, Yagasaki H, Takahashi Y, Muramatsu H, Hama A, Tanaka $\mathrm{M}$, et al. Late-onset non-infectious pulmonary complications following allogeneic hematopoietic stem cell transplantation in children. Bone Marrow Transplant 2009;44(5):303-308.

14. Esan A, Hess DR, Raoof S, George L, Sessler CN. Severe hypoxemic respiratory failure: part 1: ventilatory strategies. Chest 2010;137(5): 1203-1216.

15. Raoof S, Goulet K, Esan A, Hess DR, Sessler CN. Severe hypoxemic respiratory failure: part 2: nonventilatory strategies. Chest 2010; 137(6): 1437-1448.

16. Moscatelli A, Ottonello G, Nahum L, Lampugnani E, Puncuh F, Simonini A, et al. Noninvasive ventilation and low-flow venovenous extracorporeal carbon dioxide removal as a bridge to lung transplantation in a child with refractory hypercapnic respiratory failure due to bronchiolitis obliterans. Pediatr Crit Care Med 2010; 11(1):e8-12.

17. Leahey AM, Bunin NJ, Schears GJ, Smith CA, Flake AW, Sullivan KE. Successful use of extracorporeal membrane oxygenation (ECMO) during BMT for SCID. Bone Marrow Transplant 1998;21(8):839-840.

18. Morris SH, Haight AE, Kamat P, Fortenberry JD. Successful use of extracorporeal life support in a hematopoietic stem cell transplant patient with diffuse alveolar hemorrhage. Pediatr Crit Care Med 2010;11(1):e4-e7.

19. Brodie D, Bacchetta M. Extracorporeal membrane oxygenation for ARDS in adults. N Engl J Med 2011;365(20):1905-1914.

20. Combes A, Bacchetta M, Brodie D, Muller T, Pellegrino V. Extracorporeal membrane oxygenation for respiratory failure in adults. Curr Opin Crit Care 2012;18(1):99-104. 